\title{
Agency in the face of path dependence: how organizations can regain scope for maneuver
}

\author{
Johann Fortwengel ${ }^{1}$ (D) Arne Keller $^{2}$
}

Received: 29 September 2019/Accepted: 24 June 2020/Published online: 4 July 2020

(C) The Author(s) 2020

\begin{abstract}
This paper tackles a key problem in path dependence research: how can locked-in organizations regain their scope for maneuver? Leveraging insights from two surprising and thus revelatory cases of organizations that have successfully escaped from path dependence, we develop the theoretical argument that regaining scope for maneuver can be achieved by interrupting the logic of a path's underlying self-reinforcing mechanisms. More specifically, we argue that, through a targeted interruption of the working of these mechanisms, hyper-stable patterns inscribed in an organization can be gradually rewound-and alternative futures become possible. We position our paper within larger debates around the role of agency in path dependence theorizing, and we outline research frontiers to better understand the necessary antecedents of and exact relationship between mechanisms interruption and pattern unwinding.
\end{abstract}

Keywords Path dependence - Self-reinforcing mechanisms · Lock-in · Agency

Johann Fortwengel and Arne Keller have contributed equally and are listed alphabetically.

Johann Fortwengel

johann.fortwengel@kcl.ac.uk

Arne Keller

arne.keller@jku.at

1 King's Business School, King's College London, Bush House, 30 Aldwych, London WC2B 4BG, UK

2 Institute of Leadership and Change Management, Johannes Kepler University Linz, Altenberger Straße 69, 4040 Linz, Austria 


\section{Introduction}

It is increasingly understood that organizations can be caught in hyper-stable behavioral patterns, in the process showing puzzling persistencies and inertia. To explain this phenomenon, the theory of organizational path dependence has gained traction (Schreyögg and Sydow 2011; Schreyögg et al. 2011; Sydow et al. 2009; Vergne and Durand 2010). This theoretical lens, which originates in the field of historical and institutional economics (Arthur 1989; David 1985), describes how a single or multiple organizations together can get caught up in self-reinforcing dynamics and ultimately become locked-in. While research over the past three decades has provided us with a better understanding of the developmental processes, materializations, and intricate consequences of path dependence, one key unresolved issue pertains to the question of agency in path dependence. While there is broad agreement that agency is important at the early stages of the process, when actors trigger self-reinforcing mechanisms and increasing returns, we know significantly less about agency at the back end, in particular during and after the lock-in stage (Sydow et al. 2009). Previous work describes the tapering process through which the scope of action increasingly narrows, and how agency at the back end merely takes the form of path stabilization and (pathological) reproduction (e.g., Koch 2011; Wenzel 2015) or, if any, only 'horizontal creativity' (Rothmann and Koch 2014); and that destabilizing a path requires an external shock (David 1986) or a series of external 'macro' events (Wenzel et al. 2017). In consequence, the key research problem of whether and how path-dependent entities may actively escape from paths is largely left unanswered. Advancing our knowledge in this realm is important for two main reasons. First, from an empirical standpoint, we know that some organizations succeed in escaping from path dependence against all odds, but we have an underdeveloped theoretical understanding of how and why this may be the case. Second, from a theoretical standpoint, a better understanding of this phenomenon can add important nuance and additional richness toward uncovering the complex relationship between agency and the theory of path dependence. Indeed, as argued by Martin (2010), a better theory-immanent conceptualization of agency in and after the lock-in stage promises to realize the potential of path dependence as an evolutionary construct.

In this paper, we tackle this important research puzzle, seeking to contribute to the understanding of how path-dependent organizations can broaden their choice set and thus regain previously lost scope for maneuver. In their seminal paper, Sydow et al. (2009: 702) state that "escaping from or breaking a path depends very much on interrupting the logic and the specific energy of the self-reinforcing patterns of the process in question." However, it remains unclear how exactly organizations can accomplish this, and why the interruption of the 'logic and energy' would enable escaping from the path. To fill this gap and further advance path dependence theorizing, we address the following research question: How does the interruption of self-reinforcing mechanisms enable path-dependent organizations to regain scope for maneuver? 
Studying two surprising and thus revelatory success cases of organizations that have been able to regain scope for maneuver after being locked-in, we reveal how the effective interruption of self-reinforcing dynamics involves active and targeted engagement with a path's underlying positive feedback mechanisms (Dobusch and Schüßler 2013). Importantly, our empirical analysis allows us to develop theorization on how and why interrupting the logic is productive for regaining scope for maneuver. Drawing on the idea that path-dependent patterns are inscribed in formal and informal organizational structures (Koch 2011), we show how mechanisms interruption constitutes a key lever, over time, to overcome the organizational inscription of a path. Specifically, our empirical findings, which we replicate across our two cases (Eisenhardt and Graebner 2007), indicate that by interrupting the 'logic and energy' of a path's underlying self-reinforcing mechanisms, organizations can trigger and sustain a process whereby the pathdependent pattern is gradually undone.

Our paper contributes to the literature on organizational path dependence in two main ways. First, we map existing research and identify two broad schools of thought, which differ in how they conceive of the role of agency in processes of path dependence: a 'weak' and a 'strong' view on path dependence. Building on this mapping, and taking a strong view on organizational path dependence (Sydow et al. 2009), our second main contribution lies in advancing our understanding of how exactly agency is possible in the face of path dependence. Here, we add nuance to the conceptual argument that once organizations are locked-in, regaining scope for maneuver requires the interruption of the path's underlying self-reinforcing mechanisms. More specifically, we show how this interruption is enabled by an 'external lens,' and how in and through mechanisms interruption organizations can, over time, overcome the path inscribed in both formal and informal structures of the organization (cf., Koch 2011). As such, mechanisms interruption emerges as a lever to gradually rewind an organizationally inscribed path-dependent pattern. Combined, we thus offer a temporal view on how organizations can regain scope for maneuver, with mechanisms interruption and 'reversing' the path inscription as two key and interrelated steps in the process. Overall, our study advances path dependence theorizing by shifting the view from the analysis of the formation and (pathological) reproduction of hyper-stable patterns to the theoretically intriguing and managerially highly relevant question of how organizations can successfully escape from path dependence.

\section{Theoretical background}

\subsection{Path dependence and self-reinforcing mechanisms}

Path dependence concerns the formation and continuation of 'rigidified action patterns' (see Sydow et al. 2009: 696), and thus draws attention to how specific events and choices at an earlier point in time affect and potentially restrict subsequent and future actions. As a process theory, it specifies how history matters in explaining puzzling persistencies in a wide variety of settings (Dobusch and 
Schüßler 2013; Vergne and Durand 2010), including individual organizations (Burgelman 2002; Schreyögg et al. 2011) or sets of multiple organizations as parts of regional clusters or inter-organizational networks (Burger and Sydow 2014; Schmidt and Braun 2015), industries and sectors (Koch 2008; Wenzel 2015), and even whole (trans-)national institutions (Berthod and Sydow 2013; David 1994; Thelen 1999). At the center of path-dependent processes are self-reinforcing mechanisms (Dobusch and Schüßler 2013; Sydow et al. 2009), which often work in conjunction to form and stabilize a path over time.

Building on David's $(1985,1986)$ and Arthur's $(1989,1994)$ seminal work on the formation, diffusion, and (puzzling) continuation of (inferior) technological standards (e.g., Cusumano et al. 1992), Sydow et al. (2009)—moving from the technological to the organizational sphere-conceptualize organizational path dependence as being driven and stabilized by four distinct kinds of self-reinforcing mechanisms: coordination effects, complementarity effects, learning effects, and adaptive expectation effects.

\subsubsection{Coordination effects}

Often used as an explanatory variable in institutional economics (North 1990), coordination effects, which result from the benefits of rule-guided behavior, "relate to the heart of organizational functioning" (Sydow et al. 2009: 699). These effects refer to the observation that interaction among different actors becomes more efficient, the more actors adopt and follow a specific rule or routine. While facilitating smooth cooperation and thus significantly reducing coordination costs, these effects also tend to bring about an increasing fixation of the once established rule or routine.

\subsubsection{Complementarity effects}

The notion of complementarity effects refers to the beneficial interplay among, and synergetic bundling of, multiple interrelated rules, routines, or resources (Pierson 2000; Stieglitz and Heine 2007). This bundling is not simply additive, but creates an additional surplus (Ennen and Richter 2010). While complementarities, which ensue in a variety of settings, such as organizational routine clusters (Kremser and Schreyögg 2016), strategic activity systems (Porter and Siggelkow 2008), interorganizational arrangements (Schmidt and Braun 2015), and institutional configurations (David 1994; Hall and Soskice 2001; Milgrom and Roberts 1990), seem solely advantageous at first glance, they may also represent 'invisible chains' (e.g., Siggelkow 2001).

\subsubsection{Learning effects}

These effects describe the circumstance that the more often a specific task is performed or a distinct operation is repeated, the more efficiently, reliably, and skillfully subsequent attempts will be accomplished (Argote 1999). As a result, further exploiting existing strengths and incrementally improving on the once 
established knowledge domains gets more and more attractive over timecompared to switching to novel learning sites beyond the beaten track (Levinthal and March 1993).

\subsubsection{Adaptive expectation effects}

This self-reinforcing mechanism builds on the notion of interactive negotiation processes and the social building of preferences for certain choices. The more actors are expected to choose a particular solution or prefer a certain kind of behavior, the more attractive it becomes to adopt this particular option, and not another (Katz and Shapiro 1985). Due to the fact that actors feel the need to 'pick the right horse' (Pierson 2000: 254) and to 'end up on the winners' side' (Schreyögg and Sydow 2011: 325), expectation building typically takes place via a virtuous (or vicious) cycle-resulting in homogenous and reliable but also exceedingly difficult to reverse expectations in regard to the behavior of others.

Overall, path dependence can be conceptualized as a dynamic social process that-driven by a single or usually a combination of different self-reinforcing mechanisms, which are "at the heart of organizational path dependence" (Sydow et al. 2009: 698) and constitute "the concept's explanatory core" (Dobusch and Schüßler 2013: 638)—develops its own pull and brings about a narrowing scope for action (cf., Burgelman 2002). Once a specific organizational, inter-organizational, or institutional pattern (see for instance Dobusch and Schüßler 2013) is established and finally locked-in, it is perpetuated and continuously reproduced (e.g., Koch 2008; Rothmann and Koch 2014; Schreyögg et al. 2011; Wenzel 2015).

\subsection{Path dependence and agency}

An issue of ongoing debate is the question of agency in path-dependent processes. As defined by Emirbayer and Mische (1998: 970) in their seminal paper, agency is "the temporally constructed engagement by actors of different structural environments - the temporal-relational contexts of action-which, through the interplay of habit, imagination, and judgment, both reproduces and transforms those structures in interactive response to the problems posed by changing historical situations." Different strands of path dependence research conceive of organizational actors' ability to 'reproduce and transform' structures in different ways. We identify two ideal-typical schools of thought, with different conceptualizations of agency over the course of path dependence: a 'weak' view and a 'strong' view, which are compared in Table 1. We acknowledge that this is a stylized overview, and that in reality, the difference between the two views may be more a matter of degree. For example, the difference in terms of agency orientation may be less of a simple, clear-cut binary relationship, and more a question of which orientation is largely in the foreground and which is more in the background, and how this may possibly change over the course of the process. ${ }^{1}$ With this caveat in place, we see value in

\footnotetext{
1 We thank one of the anonymous reviewers for making this important point. See also Emirbayer and Mische (1998: 971-972).
} 
Table 1 A stylized comparison of weak and strong views on path dependence

\begin{tabular}{|c|c|c|}
\hline Dimension & Weak view & Strong view \\
\hline Front end & $\begin{array}{l}\text { Path creation (e.g., Garud and } \\
\text { Karnøe, 2001; Garud et al. } \\
\text { 2010) }\end{array}$ & $\begin{array}{l}\text { Path constitution (e.g., Sydow et al. } \\
\text { 2010; Sydow et al. 2012b) }\end{array}$ \\
\hline Back end & $\begin{array}{l}\text { Path as a resource (e.g., Teece } \\
\text { et al. 1997; Suddaby et al. } \\
\text { 2020) }\end{array}$ & $\begin{array}{l}\text { Path as a constraint (e.g., Koch, 2011; } \\
\text { Schreyögg et al. 2011) }\end{array}$ \\
\hline $\begin{array}{l}\text { Awareness and control of } \\
\text { the processual } \\
\text { dynamics }\end{array}$ & $\begin{array}{l}\text { Known and principally in actors' } \\
\text { managerial control }\end{array}$ & $\begin{array}{l}\text { Largely hidden and increasingly beyond } \\
\text { actors' managerial control over time }\end{array}$ \\
\hline Underlying ontology & Insider & Outsider \\
\hline Agency orientation & Projective, practical evaluative & Iterational, habitual \\
\hline
\end{tabular}

offering a more stylized and ideal-typical account for the purpose of introducing these two broad views.

Scholars taking a weak view emphasize the role of agency in purposely triggering and actively managing an evolving path-dependent process. An often mentioned example concerns technological standard-setting dynamics, which are deliberately initiated and steered by one or multiple organizational actors (cf., Garud et al. 2002). A key assumption of this school of thought is that organizations and organizational decision makers are principally aware of path-dependent processes and have the (full) ability to influence and purposely shape the underlying selfreinforcing mechanisms to their benefit. Therefore, research taking a weak view follows an insider's ontology. Correspondingly, Garud et al. in their work on path creation, note that " 'self-reinforcing mechanisms' are strategically manipulated" (2010: 760). In a similar vein, Vergne and Durand argue that managers act 'above and beyond' routinization and path building and are thus readily able to intentionally initiate, curb, and refocus path formation processes "[b]y favoring certain self-reinforcing mechanisms over others" (2011: 374). Similarly, this view also means that policymakers are conceptualized as being able to actively create agglomeration effects and hence steer cluster formation processes (see also Martin and Sunley 2006) by, for instance, attracting and bringing together (the investments of) critical players. In addition to this attention towards path creation (Garud and Karnøe 2001; Garud et al. 2010), scholars taking a 'weak' view on path dependence also emphasize how paths constitute a useful resource at the back end of the process (i.e., once they become firmly established). For example, Teece et al. (Teece, Pisano, and Shuen 1997: 509) argue that a firm's competitive advantage is based on the evolutionary "path(s) it has adopted or inherited." More broadly, there is a growing stream of literature that conceives of history- "the idiosyncratic nature of organizations" (Vergne and Durand 2011: 369) — as a strength and even potential 'source of dynamism' (Salvato and Vassolo 2018, see also Suddaby et al. 2020 and Suddaby and Foster 2017), as opposed to a constraint. Intriguingly, from this perspective, the past offers building blocks for engaging in interpretative and 
narrative strategies 'in the present and for the future' (see Suddaby et al. 2020). We thus establish that a weak view on path dependence involves an analytical focus on practical-evaluative and projective orientations toward the present and the future (Emirbayer and Mische 1998). At the front end of a path-dependent process, this involves strategic action aiming for deliberate path creation, while at the back end, the weak view considers the 'past' and paths as a resource for envisioning and working toward an imagined future. Scholars in this tradition thus conceive of path dependence - not only at the outset but also at later points in time (e.g., Teece et al. 1997; Vergne and Durand 2011) — as a resource that can be deliberately influenced and strategically used (see also Arthur 1996; Duschek 2010).

In contrast, a strong view on organizational path dependence involves a much narrower view on agency. From this perspective, more often than not processes of path dependence unfold accidentally and are the consequence of a rather 'small event;' an often inconspicuous (only in hindsight noticeable) trigger that constitutes a 'critical juncture' (Collier and Collier 1991). While agency is thus critical at the front end of the process in terms of (intentionally or not) triggering the constitution of an organizational path (cf., Sydow et al. 2010, 2012b), it often entails largely unintended consequences (Giddens 1984). Correspondingly, and in line with an outsider's ontology, a key assumption in this school of thought is that the ensuing self-reinforcing mechanisms "often unfold behind the backs of the actors" (Schreyögg and Sydow 2011: 322); that these mechanisms reflect "unintended consequences of former decisions" (Sydow et al. 2009: 696); and that they entail "(often overlooked) collateral side effects" (Petermann et al. 2019: 641; parentheses in the original) which can "bring about an escalating situation with unexpected results" (Schreyögg and Sydow 2011: 322). Consequently, Dobusch and Schüßler (2013: 618) note that path dependence "deliberately decentralizes agency by referring to a system logic of self-reinforcing processes triggered by contingent events." From a strong view, path dependence is a dynamic social process involving (dramatically) diminishing scope for alternative behaviors, eventually leading to a quasi-deterministic fixation and continuation (i.e., a lock-in) of a specific 'rigidified action pattern' (Sydow et al. 2009). As such, a strong view on path dependence emphasizes the iterational and habitual dimension of agency (Emirbayer and Mische 1998)_once locked-in, path-deviant behavior becomes virtually impossible, as actors are trapped in the path-dependent process (Sydow et al. 2009).

Several empirical studies have revealed the processes and intricate consequences of how specific action patterns emerge, stabilize, and become deeply embedded in organizational practice over time (see Table 2 for an overview of key empirical studies from a strong view on organizational path dependence).

These studies show how organizations (individually or collectively) become trapped in self-reinforcing dynamics (working either mostly at the organizational, inter-organizational, or institutional level) (cf., Dobusch and Schüßler 2013), and how their scope for action narrows as alternative choices become increasingly marginalized over time (e.g., Burger and Sydow 2014; Koch 2008; Schreyögg et al. 2011). Research has also revealed that self-reinforcing mechanisms and the resulting paths become gradually inscribed into the 'social fabric' of organizations (Koch 2011), and how path-dependent organizations tend to stabilize and 


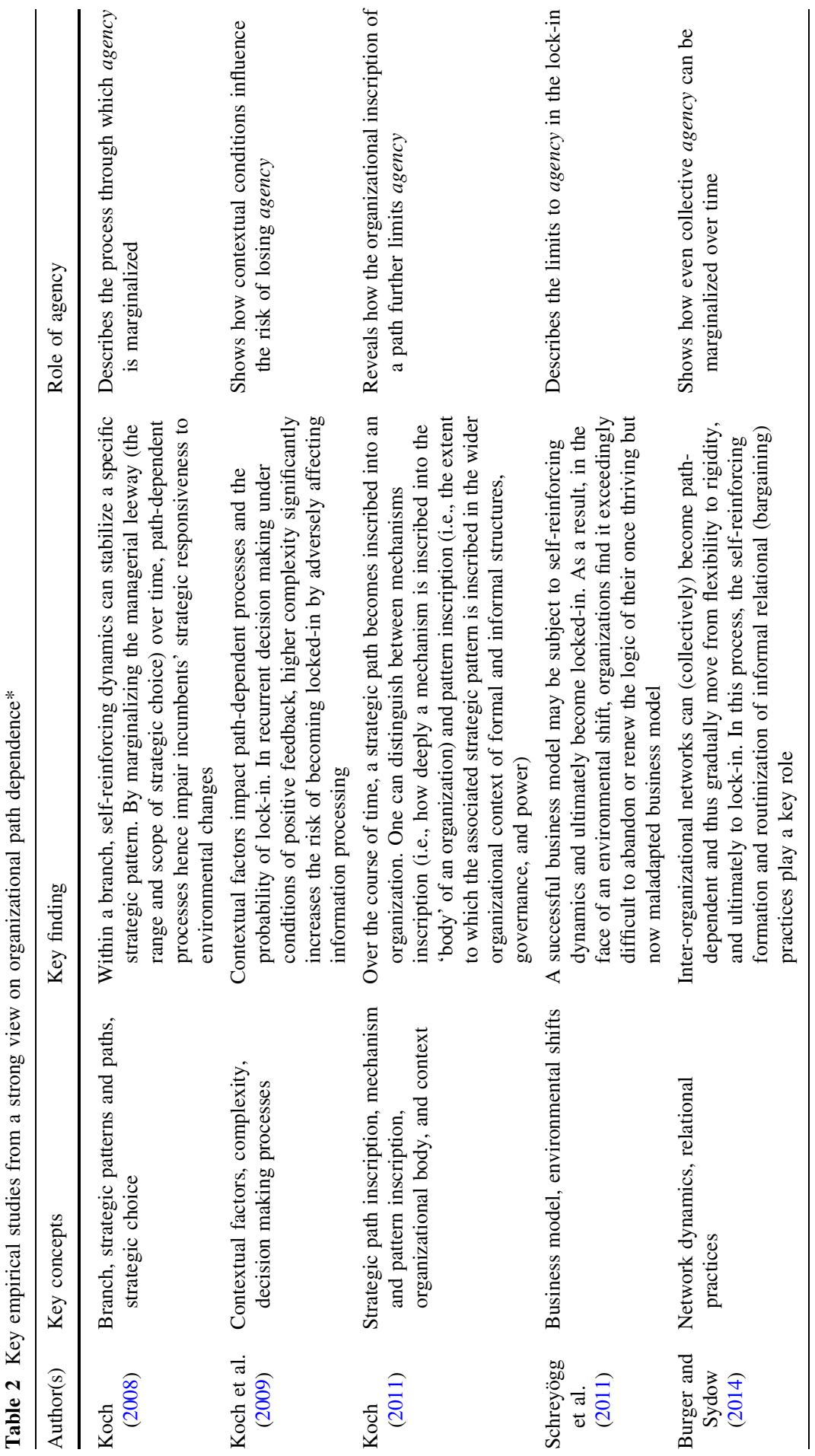




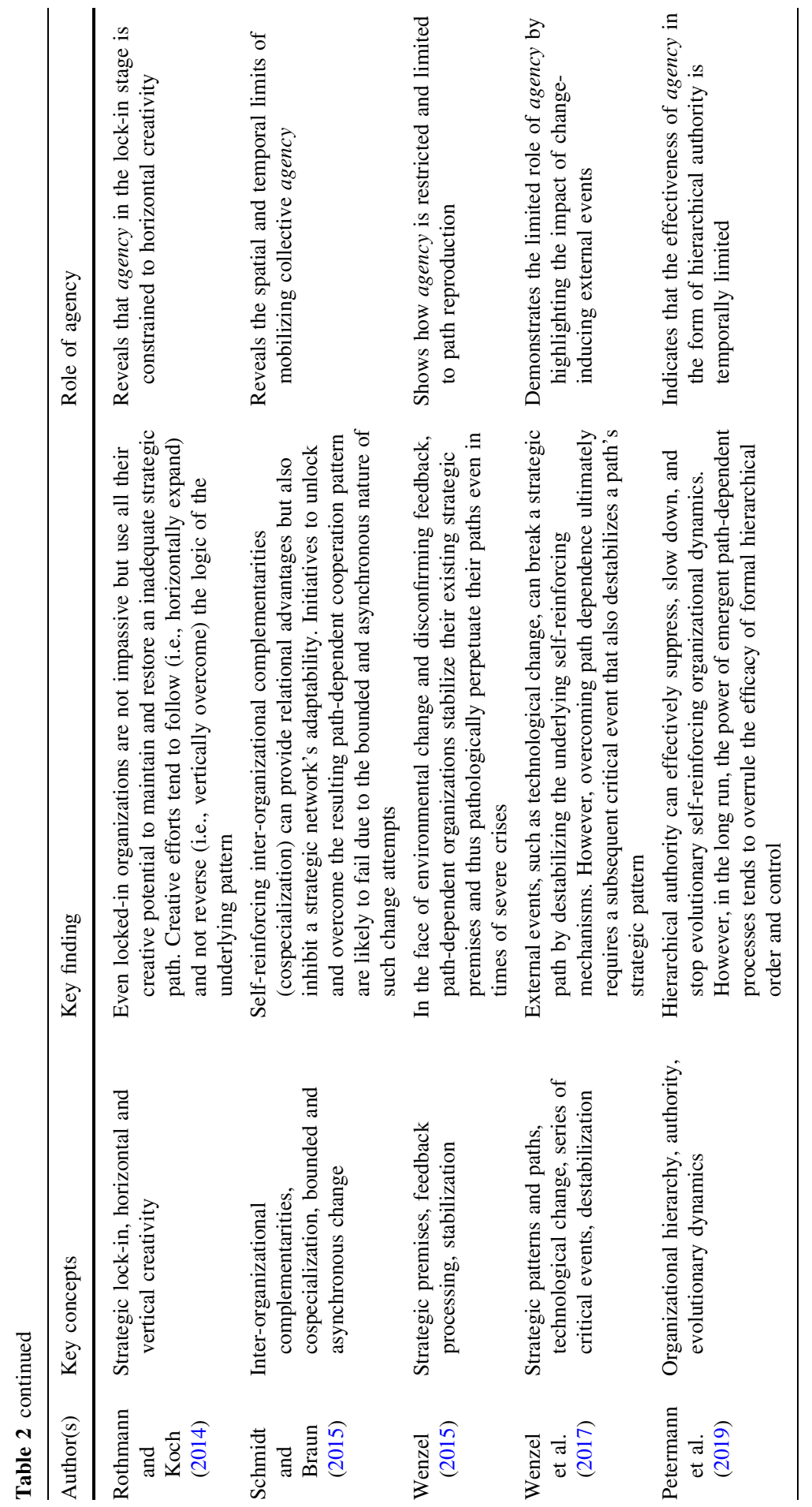




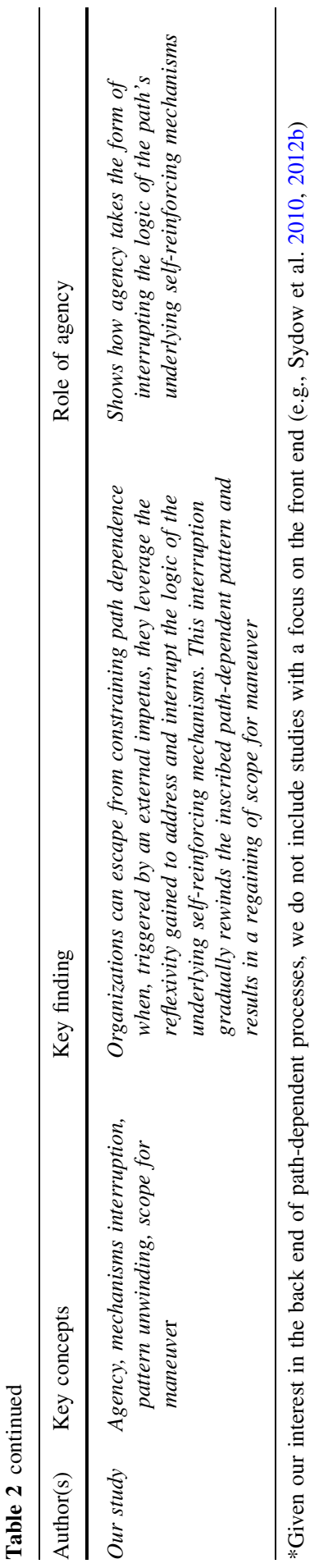


(pathologically) perpetuate a 'rigidified action pattern,' even in times of eruptive (environmental) changes and severe crisis (Wenzel 2015). However, proponents of the strong view do not conceptualize organizational actors as totally bound and 'impassive' (see also Sull 1999), either, as they acknowledge that even pathdependent patterns need to be enacted and reproduced, at times even quite creatively (Rothmann and Koch 2014). While this suggests 'change in organizations,' it does not lead to 'change of organizations' (see Tsoukas and Chia 2002: 580).

In consequence, research in the tradition of a strong view on path dependence highlights the intricate constraints faced by path-dependent entities. The overview of extant research also illustrates that while the role of agency has increasingly moved into the focus of path dependence theorizing, there is still a dearth of studies looking for spaces and possibilities of more active agency involving effective attempts to deviate from a 'rigidified action pattern' and thus regain previously lost scope for maneuver. While Sydow et al. (2009: 702) suggest that this will involve "interrupting the logic and the specific energy of the self-reinforcing patterns," we have, however, to date only limited knowledge of how exactly path-dependent organizations may accomplish this, and why exactly the interrupting of a path's selfreinforcing mechanisms enables the capture of alternative options and thus the overcoming of path dependence. In addition, while previous research also highlights the role of exogenous forces (see Arthur 1994) that "are likely to shake the system, thereby causing the organization to break away from the path" (Sydow et al. 2009: 701), it remains unclear exactly how a focal organization could leverage such an (external) shock. More specifically, we still know little about the process through which an external impetus, for example in the form of an outsider's (hierarchical) intervention (cf., Petermann et al. 2019) or a series of (destabilizing) events (Wenzel et al. 2017), effectively 'works through' the path-dependent organization to enable a sustained interruption of the logic and energy of a path's underlying self-reinforcing mechanisms. With this paper, we seek to contribute to filling this key research gap in path dependence theorizing.

\section{Methods and data}

\subsection{Research design and case selection}

We utilize a qualitative methodology because of its advantages in unpacking socially complex activities and process phenomena (Langley et al. 2013), such as the formation and organizational manifestation of paths, as well as the process of possible escape from path dependence over time. Siggelkow (2007), for instance, explicitly notes that to capture "dynamic processes (e.g., path dependency or evolutionary processes), rich longitudinal research is needed to provide the details of how these processes actually play out" (2007: 22; parentheses in the original). Our study follows the logic of theory elaboration and extension (Lee 1999), as we aim to refine and further develop path dependence theorizing (Sydow et al. 2009) by zooming in on the possibilities of regaining scope for maneuver at the back end of a path-dependent process, i.e., once an organization has become locked-in. 
In this paper, we study two cases of organizations that have been subject to and constrained by path-dependent processes, but-surprisingly enough-were successful in regaining scope for maneuver. Path dependence, as a particular kind of persistence among various other forms of organizational stability (see Sydow et al. 2009), can be considered a 'rare disease,' and organizations that successfully overcome path dependence are even rarer, making small-N qualitative case study research particularly suited for theory elaboration and extension (Eisenhardt 1989; Siggelkow 2007).

Path dependence can occur and thus can be analyzed "on the (lower resp. higher) levels of organizational subsystems or organizational fields" (Schreyögg et al. 2011: 86; parentheses in original). In this study, we leverage this idea of organizational path dependence as a cross-level phenomenon. We examine CameraCorp and EnergyCorp as two surprising success cases (Yin 2017) of organizations that faced, but were ultimately able to disengage themselves from path-dependent dynamics; being mostly rooted at the organizational (CameraCorp) or institutional (EnergyCorp) level. In our case selection and analysis, we follow a replication logic (Eisenhardt and Graebner 2007), meaning that we leverage insights from studying two revelatory cases (Yin 2017) to build more robust findings regarding the ability of organizations to escape from path dependence and regain previously lost scope for maneuver.

Previous research makes the argument that empirical studies on organizational path dependence frequently start out from a strong 'path assumption' (cf., Koch 2011; Wenzel 2015)-i.e., with a reasonable suspicion that a concrete and observable form of (organizational, inter-organizational, or institutional) rigidity may be grounded in self-reinforcing mechanisms, and thus characterized by a pathdependent process (Sydow et al. 2009). Our cases, CameraCorp and EnergyCorp, suggested such a path assumption. The tradition-steeped camera maker CameraCorp - characterized by extraordinary success in building analog cameras-was struggling dramatically to adapt to the digital photographic revolution, in a very similar way to Polaroid (Tripsas and Gavetti 2000), which is often cited as an exemplary case of organization-level path dependence (e.g., Sydow et al. 2009: 699). EnergyCorp is a large multinational corporation (MNC) from Germany, and its foreign subsidiary in the U.S. was facing the existing institutional path in the domain of vocational training (Thelen 2004). Previous research establishes that "[e]ven new entrants into [a] field of action have to adopt" (Schreyögg et al. 2011: 85) the predominant action pattern associated with an existing path. Mirroring this argument, we find that when EnergyCorp entered the U.S., it had to adopt the dominant vocational training patterns. However, when one of its subsidiaries faced a rising demand for skilled labor, the 'predominant action pattern' in the realm of recruiting and training proved insufficient to meet the changed demand. As we explore further below, an external lens created a necessary degree of reflexivity in both companies, thereby allowing a process of successful interruption of the particular logic of the self-reinforcing mechanisms of the path-dependent process that the two companies were facing, ultimately resulting in path-deviant behavior. As such, CameraCorp and EnergyCorp constitute suitable research sites to address our research question. 


\subsection{Data collection and analysis}

We collected various qualitative data from different sources. Following the example of previous case-based research on organizational path dependence (e.g., Burgelman 2010; Burger and Sydow 2014; Koch 2011; Schmidt and Braun 2015; Wenzel 2015), our main data sources are semi-structured interviews. In total, we draw on 56 interviews across our 2 cases of CameraCorp $(n=29)$ and EnergyCorp $(n=27)$. All interviews were tape recorded, transcribed verbatim, and added to a comprehensive case study database (Yin 2017). Respondents cut across different functional as well as hierarchical levels. For example, we interviewed both current and former members of the top management team of CameraCorp as well as engineers and front-line production workers. Similarly, we conducted interviews with representatives from EnergyCorp in both Germany and the U.S., involving top and middle managers as well as training managers and front-line instructors.

Interviews were semi-structured and contained questions aiming to comprehend both the challenges concerning the persistencies and path-dependent dynamics experienced by the two organizations, and how they were ultimately able to address and overcome them. For example, we asked CameraCorp respondents how they perceived and responded over time to the emergence of digital imaging and about the difficulties experienced (cf., Tripsas and Gavetti 2000), and we asked EnergyCorp respondents, in particular at the level of the U.S. subsidiary, questions aiming to reveal how they had adopted and became constrained by the 'predominant action pattern' grounded in path-dependent vocational training institutions (cf., Thelen 2004), and how they attained reflexivity through headquarters, paving the way for path-deviant behavior.

Our interview data were supplemented with publicly available as well as internal archival material. Specifically, historical annual reports, newspaper articles, government regulations, company chronicles, presentations, and press releases were collected and analyzed. These documents enabled us to trace back and comprehend the historical (path-dependent) developments and the formation and (organizational) manifestation of self-reinforcing dynamics over time. In addition, by facilitating data triangulation they also allowed us to mitigate potential retrospective biases, such as ex-post rationalization or impression management, which might occur when using interview data to reconstruct (long-term) historical events (Eisenhardt and Graebner 2007). Overall, the data collected enabled us to engage in a history-sensitive analysis of the processes of path formation, logic interruption, and the unwinding of the inscribed path-dependent pattern (Kieser 1994; Kipping and Üsdiken 2014).

Our data analysis, while not proceeding in a linear but iterative fashion, involved three main steps. Unlike in research aiming for grounded theory building (cf., Glaser and Strauss 1967), our data analysis - striving for theory elaboration and extension (Lee 1999) — was theoretically informed by the core concepts of path dependence theorizing (see Sydow et al. 2012a). In a first step of data analysis, we thus sought to confirm our initial path assumption. For this purpose, we reconstructed the formation of the path-dependent pattern in our two cases, involving the emergence, triggered by a critical event, and stabilization of a 
particular dominant pattern and its continuation and temporal persistence-despite recurrent change efforts. Because path-dependent processes "can be explained by one or a combination of several self-reinforcing social mechanisms" (Sydow et al. 2009: 698), we paid particular attention to the identification, working, and structural manifestation (i.e., organizational inscription (Koch 2011)) of these mechanismsand how they diminished actors' scope for maneuver.

In a second step, we then sought to examine exactly how CameraCorp and EnergyCorp were able to regain scope for maneuver and deviate from the existing paths they were facing. Here, we reconstructed exactly how these two organizations accomplished an interruption of the logic and energy of the underlying selfreinforcing mechanisms. Importantly, we made the observation that this involved leveraging an external lens in both cases: while CameraCorp's engagement with the self-reinforcing mechanisms was enabled by the impetus of a new strategic investor, EnergyCorp's structure as an MNC introduced the necessary reflexivity at a particular point in time to imagine an alternative future. Importantly, we also traced how the interrupting of the self-reinforcing mechanism 'worked through' the organization, gradually resetting the previously inscribed path-dependent pattern in the process (Koch 2011).

In a third and final step, after we had analyzed each case individually, we engaged in a cross-case comparison to leverage insights across both cases (Eisenhardt and Graebner 2007). Our research design involving two revelatory success cases (Ozcan, Han, and Graebner 2017; Siggelkow 2007), which both show how an organizationally inscribed path-dependent pattern can be gradually rewound through targeted mechanisms interruption, allowed us to build a more robust contribution in the realm of agency in path dependence theorizing from a strong view.

\section{Findings}

\subsection{CameraCorp}

\subsubsection{Diminished scope for maneuver}

CameraCorp is a specialized, relatively small, yet world-renowned German camera manufacturer. The company's historical roots go back for more than 150 years. Originally developing and commercializing opto-mechanical instruments, such as telescopes, and eventually becoming known for the production of advanced microscopes, the firm was a major pioneer of celluloid, film-based photography. In the mid-1920s, CameraCorp launched one of the first portable photo cameras and established the well-known $35 \mathrm{~mm}$ 'Kleinbild' format. Notably, the camera's prototype as well as the specific film format stemmed from the daring ingenuity of the firm's technical director, who was — without being commissioned-experimenting with pieces of cinematic film to build a handy roll film camera. Displacing the then predominant heavy and cumbersome plate cameras, the firm's small and lightweight opto-mechanical masterpieces revolutionized the field of photography. 
CameraCorp rapidly became a household name and an icon of photography with enthusiastic fans all over the world.

The invention and launch of the first photo camera turned out to be the critical triggering event for the onset of a path-dependent process. Subsequently, the firm developed into a distinct camera manufacturer. Set off by the rather incidental technical invention and the owner family's bold decision to bring the small and handy, at that time revolutionary camera to the market, the path formation-driven by the immediate and resounding commercial success-was (further) accelerated through the onset and complex interaction of distinct self-reinforcing mechanisms. The operation of these mechanisms spurred and continuously reinforced the path formation process - thereby inadvertently pushing the firm along a narrowing trajectory with an increasingly diminished scope for maneuver.

CameraCorp's employees gradually followed the informal principle to treat optical excellence and mechanical accuracy as the fundamental basis for decisionmaking, and adopted it as the ultimate priority in every aspect of their daily work. Resulting in well-tuned and hence highly efficient informal interaction patterns between different departments and employees, the evolving coordination effects, however, also steadily marginalized deviating approaches and behaviors. As a result, alternative and inconsistent perspectives and initiatives faced more and more problems in getting the necessary attention and support, making it progressively difficult to reverse or deviate from the well-attuned rules centered on optomechanical excellence. CameraCorp's Head of Electronics, who entered the firm in the mid-1990s, for instance, reported on his experience of trying to alter the firm's proven R\&D principles and to integrate electronics into the optical lenses of the company's single-lens reflex camera: "I encountered resistance. I met persons and managers who stated that these lenses do not need this, as they have been functioning mechanically for more than twenty years, and that electronics is completely unnecessary" (Head of Electronics). The continuous practice of these (inter)departmental rules and principles not only yielded a well-established, deeply embedded informal order; it also spurred the development of complex complementarities between (synergistic) technical choices, organizational routines, and resources. As a consequence, in interaction with the demand side as well, where faithful customers were gradually building up valuable collections of matching optical lenses, these complementarity effects generated an increasingly fixed product architecture around the $35 \mathrm{~mm}$ 'Kleinbild' format with widely ramified technical as well as organizational complementarities. Furthermore, learning effects in the development and serial production of high-end opto-mechanical cameras yielded distinct capabilities in fine optics and precision mechanics. Reaping the benefits of exploiting and further incrementally refining these strengths, CameraCorp was focusing progressively on a few, highly specialized knowledge domains (e.g., aspheric lens technology, high sensitive glasses, and lens assembling), while increasingly neglecting more explorative and distant learning activities: "We had the money only once. We could not spend it twice. We therefore invested further in optical aspheres technology, rather than exploring the electronic autofocus, for example" (Head of Optics Development). Lastly, CameraCorp's employees also gradually built-up specific and over time increasingly dominant expectations about 
the expectations of others. Dominant and deeply rooted assumptions concerned the cameras' non-negotiable quality and precision, and that the firm's customers valued prime opto-mechanical quality and consistency rather than ever-new features and ongoing innovations: "It was common within the company to say that CameraCorp's cameras are sold because the customers value the fine mechanics and the optics" (Head of Electronics). Hence, the firm was characterized by a more and more taken-for-granted (self) identity and (public) image centered on craftsmanship, technical purism, and opto-mechanical excellence.

Over the course of time, all this amounted to a tapering, increasingly difficult to escape technological but above all organizational trajectory with a very limited range of variation. Over the decades, CameraCorp's path had become more and more deeply inscribed into the organization and hence became increasingly fixed, as nearly all new, deviant trends and alternative perspectives were overlooked or rejected. Declining sales in the 1980s, opto-mechanically brilliant but technically more and more antiquated products, as well as failed (endogenous) change initiatives and repeated rejections of off-path activities, such as the dismissal of alternative $R \& D$ priorities or the thwarted exploration and adoption of innovative features (e.g., autofocus technology, electric film transportation, etc.), already indicated CameraCorp's path-dependent rigidification, and ultimately it became dysfunctional, and hence the problem became fully visible in light of a fundamental change in the firm's business environment.

In the course of the digital photographic revolution, picking up steam in the late 1990s, CameraCorp, like never before, was pushed to alter and depart from its timehonored, internally well-aligned but externally increasingly maladapted, organizational path. The emerging digital imaging technology transformed a photo camera from an opto-mechanical instrument into a complex electronic device. By implication, development and production, instead of relying first and foremost (still) on fine-optical and precision-mechanical expertise, now demanded fundamentally different procedures, involving new technological know-how in microelectronics, digital circuit design, image processing, and software engineering.

Remarkably, CameraCorp, despite its tradition-steeped opto-mechanical heritage and strong path-dependent dynamics at work, sensed the emerging trend quite early on and started to explore the emerging digital technology by establishing a structurally separate digital imaging group in 1994. While the highly dynamic research group located in the surroundings of a local technical university was regarded with considerable suspicion and doubt, it succeeded in developing leadingedge digital know-how (including functional prototypes and even first digital camera products). However, CameraCorp's path-dependent core organizationbeing marked by the working of strong self-reinforcing mechanisms-eventually refused the adoption and integration of alternative $R \& D$ priorities and divergent engineering practices: "Within our structure the problem was integration. If you want to make a digital system, suddenly everything is interconnected. (...) Thus, the opinion disseminated: 'Building a digital camera; Oh my God, please don't.' No one dared to develop something really new” (Project Manager).

Similarly, a longstanding production worker noted: 
"The then management was not able to establish confidence at CameraCorp that we could run a new digital system as well as high-end mechanical and optical systems in parallel. (...) At CameraCorp if you wanted to change the smallest detail, then it created the greatest uproar. Even if it had been just a single screw. The people replied, 'It is not possible,' and they would resist" (Production Worker).

The firm eventually followed a distinct analog-retro strategy (similar to mechanical Swiss watches or old-fashioned 'vintage' record players). By implication, CameraCorp was continuously reproducing and pathologically perpetuating its entrenched, rigidified action pattern-despite drastically declining revenues and mounting losses. In the mid-2000s, CameraCorp-experiencing a more and more dramatic misfit of its established path (geared towards developing and producing high-precision opto-mechanical analog cameras) and the surrounding market environment-was on the brink of bankruptcy.

\subsubsection{Regaining scope for maneuver}

In the midst of these developments, a new strategic investor bought a majority stake in the company. This external investor, who for some time even acted as executive director, opted for and enforced a radical response to the ever more rapidly unfolding digital revolution. As noted by an employee representative:

"If [name of investor] had not come, we would have never been able to depart from our established routine. We would have been extinct. (...) A major shareholder pushed us in a certain direction. Unfortunately, the company by itself was not able to perceive the situation. The firm simply tried to hold on using life-saving measures. Nobody had the guts to go in this or that direction" (Chairman of the Works Council).

Offering an external lens and also being equipped with the necessary (financial) resources, the investor, entering the company in 2004, was able to 'perceive the situation' as requiring action. Specifically, the new investor started and insistently drove activities that addressed the working of existing self-reinforcing mechanisms, to overcome the prevailing resistance and so transition CameraCorp into the digital age.

For one, by campaigning for and supporting previously scorned engineering disciplines (most notably the electronic and digital developers) and by resetting the established (interdepartmental) working processes and R\&D priorities, and thus reshuffling the firm's 'informal order,' the predominant organizing principle to focus solely on optical excellence and mechanical accuracy was dissolved. This fundamentally dismantled existing coordination effects. The Head of Electronics, for instance, recounts this radical switch by stating:

"In the past, optical performance constituted the ultimate objective. (...) The impact [of electronics] has clearly changed. We electronics technicians are already involved in the product specification phase. From the start, we have interdisciplinary teams" (Head of Electronics). 
This overcoming of the preexisting informal rule set enabled the established but, in particular, the increasing number of new digital imaging developers to consider and choose from a broad(er) range of technical options and thus to explore and eventually integrate several innovative (electronic) features into the newly developed digital camera models.

In addition to opening up the established cluster of existing routines and resources - that is, accepting misfit costs in respect to discontinued complementarities at the organizational level-the investor forced the company to break with its existing lens system for the first digital model, thereby accepting the (at least temporary) loss of the existing complementarities on the customer side. More specifically, he used his power as the majority stakeholder to decide and enforce a temporary departure from the dominant $35 \mathrm{~mm}$ format using a smaller digital imaging sensor for the firm's first digital camera. Due to strong compatibility requirements, and the firm's longstanding historical roots, which had also yielded very specific expectations about customer preferences, similar attempts in the past had repeatedly been rejected. Besides actively addressing and unlocking existing coordination and complementarity effects and thus interrupting and discontinuing the working of these path-stabilizing mechanisms, broadening the scope for maneuver was also facilitated by substantial investments and a radical shift in resource allocation from existing, exploitative to novel, explorative learning domains:

"What [name of investor] had done was to push towards digital technology.

That means that CameraCorp not only provides the mechanics and the optics-and other [firms] do the electronics. He defended the position that: 'Someday, a camera will be an electronic device with nice components all around. You consequently have to master electronics"'(Head of Digital Imaging).

CameraCorp thus purposely suffered the consequences of waiving the returns linked to existing learning effects, to set off a new learning trajectory in digital imaging. This arduous process was also accompanied by collaborating with various external partners and the hiring of suitable experts in this field. Facilitated by the new investor, these measures finally triggered a gradual change of thinking in terms of employees' (adaptive) expectations about the preferences of the company's customers. For example, by altering the firm's marketing presence and strengthening the link to arts and culture, and thus partly repositioning the brand in the luxury segment, CameraCorp's employees increasingly recognized the need to tap into new and substantially different customer groups and their nascent (technical) demands, such as live view or high-definition video. Remarkably, while CameraCorp's transition was not seamless by far, but riddled with setbacks, the company successfully gained a foothold in the highly competitive digital camera market.

Table 3 below summarizes our findings on how the mechanisms underlying CameraCorp's path materialized within the organization, resulting in a diminished scope for maneuver, and how mechanisms interruption allowed the company to regain scope for maneuver by gradually rewinding the inscribed path. Set off by the 
Table 3 CameraCorp: Overview of findings

\begin{tabular}{|c|c|c|c|}
\hline \multicolumn{2}{|c|}{ Diminished scope for maneuver } & \multicolumn{2}{|c|}{ Regaining scope for maneuver } \\
\hline $\begin{array}{l}\text { Self-reinforcing } \\
\text { mechanism }\end{array}$ & $\begin{array}{l}\text { Mechanism } \\
\text { materialization }\end{array}$ & Mechanism interruption & Representative quotes \\
\hline $\begin{array}{l}\text { Coordination } \\
\text { effects }\end{array}$ & $\begin{array}{l}\text { Well-tuned informal } \\
\text { (interdepartmental) } \\
\text { interaction rules and } \\
\text { principles geared } \\
\text { towards developing } \\
\text { high-end opto- } \\
\text { mechanical cameras }\end{array}$ & $\begin{array}{l}\text { Dissolving ingrained } \\
\text { coordination rules by } \\
\text { resetting working } \\
\text { processes and R\&D } \\
\text { priorities }\end{array}$ & $\begin{array}{l}\text { "In the past, optical } \\
\text { performance } \\
\text { constituted the ultimate } \\
\text { objective. (...) The } \\
\text { impact [of electronics] } \\
\text { has clearly changed. } \\
\text { We electronics } \\
\text { technicians are already } \\
\text { involved in the product } \\
\text { specification phase. } \\
\text { From the start, we have } \\
\text { interdisciplinary } \\
\text { teams" (Head of } \\
\text { Electronics) }\end{array}$ \\
\hline $\begin{array}{l}\text { Complementarity } \\
\text { effects }\end{array}$ & $\begin{array}{l}\text { Complex bundle of } \\
\text { interrelated routines } \\
\text { and resources favoring } \\
\text { complementary } \\
\text { (technical) choices in } \\
\text { camera development } \\
\text { and use while rejecting } \\
\text { deviating ones }\end{array}$ & $\begin{array}{l}\text { Opening up the } \\
\text { established cluster of } \\
\text { routines and (technical) } \\
\text { relationships by } \\
\text { deliberately accepting } \\
\text { the resulting misfit } \\
\text { costs }\end{array}$ & $\begin{array}{l}\text { "It proved difficult to stay } \\
\text { with the } 35 \mathrm{~mm} \\
\text { 'Kleinbild' format. The } \\
\text { knot that we cut was } \\
\text { simply to use a smaller } \\
\text { [imaging] sensor" } \\
\text { (Head of Digital } \\
\text { Imaging) }\end{array}$ \\
\hline Learning effects & $\begin{array}{l}\text { Exploitation and further } \\
\text { refinement of proven } \\
\text { (opto-mechanical) } \\
\text { camera development } \\
\text { and production } \\
\text { procedures }\end{array}$ & $\begin{array}{l}\text { Undermining exploitative } \\
\text { learning by shifting } \\
\text { resource allocation to } \\
\text { novel explorative, } \\
\text { specifically digital, } \\
\text { learning domains }\end{array}$ & $\begin{array}{l}\text { "It was decided that we } \\
\text { would no longer } \\
\text { develop new analog } \\
\text { products but fully } \\
\text { commit to digital" } \\
\text { (Head of Camera } \\
\text { Development) }\end{array}$ \\
\hline $\begin{array}{l}\text { Adaptive } \\
\text { expectation } \\
\text { effects }\end{array}$ & $\begin{array}{l}\text { Taken-for-granted } \\
\text { assumption that the } \\
\text { company stands for } \\
\text { technical purism and } \\
\text { opto-mechanical } \\
\text { craftsmanship }\end{array}$ & $\begin{array}{l}\text { Shaking up ingrained } \\
\text { assumptions by } \\
\text { engaging in selective } \\
\text { activities challenging } \\
\text { the perceived 'retro } \\
\text { image' }\end{array}$ & $\begin{array}{l}\text { "From the very first } \\
\text { moment [the new } \\
\text { investor] stated that we } \\
\text { needed to go into } \\
\text { digital technology, and } \\
\text { that this was the future } \\
\text { of the photo industry. } \\
\text { From that point the } \\
\text { development prevailed. } \\
\text { However, it took some } \\
\text { time (...) until } \\
\text { everybody had } \\
\text { reframed" (Chairman } \\
\text { of the Works Council) }\end{array}$ \\
\hline
\end{tabular}


entry of a new external investor, this process eventually enabled CameraCorp to leave behind its constraining past and to actively embrace a future revolving around digital technology.

\subsection{EnergyCorp}

\subsubsection{Diminished scope for maneuver}

EnergyCorp is a large, diversified MNC from Germany. It is active in most countries in the world, and it has numerous production facilities in some key markets, including the U.S., which constitutes one of the most important foreign markets for the company. During the observation period, EnergyCorp generated revenues of about $\$ 20$ billion in the U.S. market alone. For the manufacture of its high-quality (industrial) products, EnergyCorp relies on skilled production workers, who are recruited and trained at home through Germany's dual vocational training system, which involves apprenticeships combining theoretical instruction with practical training. In the U.S., however, apprenticeships are marginalized, despite numerous attempts to increase the scale and scope of this training model (Fortwengel et al. 2019). Previous research enables the mapping of the U.S. vocational training system as an institutional path (cf., Thelen 2004). As an entrant into this 'field of action,' EnergyCorp's foreign subsidiary in the U.S. had to adopt the existing 'predominant action pattern' in the domain of workforce recruitment and training.

More specifically, the subsidiary in the U.S. faced an institutional path that was set in motion at a critical juncture, with the passing of the Immigration Act of 1924. This law was intended to limit immigration into the U.S., and an important consequence was that it constrained the availability of skilled workforce. In response, businesses in the U.S. decided to invest heavily in mass-production technology, which reduced their dependence on highly skilled workers, which were then a scarce resource. The path-dependent process in the American vocational training system was thus triggered by strategic decisions by firms to opt for a particular kind of production organization, with the largely unintended consequence of setting in motion a process resulting in diminished scope for maneuver in terms of skill development.

Over time, powerful coordination effects ensued. This involved the establishment of additional 'rules of the game,' including regulations related to the New Deal in the 1930s, which made firms fine-tune their alignment between human resources and production strategy over time, on the one hand, and led to the limited availability of skilled workforce on the other. For example, the National Apprenticeship Act of 1937 (50 Stat. 664; 29 U.S.C. 50) was largely limited to setting standards to 'safeguard the welfare' of apprentices, as opposed to creating a more comprehensive regulatory support infrastructure to facilitate the establishment of harmonized programs and certification routes. As a result, the alternative option of apprenticeship training was increasingly crowded out, and flexible on-the-job training became dominant. Notably, the formation of the institutional path became inscribed into behavioral patterns at the level of individual companies. For example, 
around that time firms in the U.S. started to show a distinct production organization, which relies more on engineers and semi-skilled workers compared to firms in other countries. Furthermore, strong complementarities emerged between institutional domains, in particular between training and education on the one hand, and the labor market on the other. Not least because of the de-emphasis on skilled workforce, training leading to more general skills became favored. This, in turn, developed to become complementary to the emerging fluid labor market, where general skills are easily tradable. Apprenticeship programs, in contrast, generate more firm- or industry-specific skills, and thus are less easily marketable. As a result, these alternative pathways became increasingly marginalized. Furthermore, over time, learning effects unfolded, meaning that the various actors involved learned to navigate in this particular institutional environment. For example, firms learnt the lesson that investments in less general skills should be avoided because workers are often poached. Moreover, companies learnt, effectively, to offer on-the-job training in-house. Overall, these conditions yielded adaptive expectations, meaning that it became widely expected that high-school graduates either opted for a 4-year college education or entered the workforce and received training on-the-job in a largely unstructured manner. College degrees are the norm in the U.S., and non-college bound education pathways are largely stigmatized, including apprenticeship. As a result, the already low number of active apprenticeship programs in the U.S. has decreased even further, and it is down by about $30 \%$ compared to some 15 years ago. $^{2}$ Another indicator is that the Department of Labor's entity regulating apprenticeships has seen its budget cut by about 50\% between 1977 and 2007, adjusted for inflation (Lerman 2010).

Paradigmatic of path dependence, previous attempts to change the workforce education and training institutions in the U.S. failed. Indeed, there were repeated initiatives to broaden the choice set, including adding German-style apprenticeships. This included both top-down and government-led initiatives during the first Clinton Administration, who sought to follow Germany as a template, as well as more local bottom-up initiatives, such as the Wisconsin Regional Training Partnership as a sector-based solution (Rogers and Parker 1996). However, these initiatives failed, and the institutions of workforce training continued on their path.

When it entered the U.S. market, EnergyCorp faced this existing institutional path, and the U.S. subsidiary serving as focal case in this study was drawn onto the path. For a considerable amount of time the U.S. subsidiary adopted the 'predominant action pattern,' meaning that it recruited its workforce on the external market and administered flexible in-house training. When significant growth created demand for a large number of skilled workers in a very short period of time, EnergyCorp's subsidiary in the U.S. was unable to meet the need, and experienced a significant skills shortage, damaging productivity and preventing it from exploiting the full growth potential.

\footnotetext{
2 https://www.doleta.gov/oa/data_statistics2018.cfm (last access: 8 April 2020).
} 


\subsubsection{Regaining scope for maneuver}

Importantly, when the entity in the U.S. faced a sudden spike in demand for production workers, it made the experience that existing 'predominant action patterns,' which had become inscribed into the organization over time were insufficient: "There were just no people who demonstrated the ability in the market” (Executive; U.S. Headquarters). In response, EnergyCorp had to

"start to develop courses, teach courses [...]. So the short-term [response] was running a lot of people through courses using that as a mechanism to select the best out of those, I think the number is around 4,300 people through the training, and employed about 800 or 900 of them" (Executive; U.S. Headquarters).

Importantly, the 'shock' of a sudden and rapid expansion triggered a thinking process about a longer-term, sustainable solution to meeting the skill demand and managing a pipeline of skilled worker talent. Here, the embeddedness within the MNC organization was critical, as home-country operations were able to direct their American colleagues towards apprenticeship as a possible solution to their local problems. As the HR Director of the focal U.S. subsidiary explains:

"Once we had exhausted our resources in a short time period, that we were not having much success with qualified candidates in the Midwest or the Southeast, that was when the decision was made, then we have got to invest ourselves through an apprenticeship program, and we have got to invest, let's invest locally" (HR Director; U.S. Subsidiary).

The HR Director as well as the rest of the top management team were American, and thus not familiar with the apprenticeship practice. An important antecedent of the 'decision to invest in an apprenticeship program', therefore, was tapping into the knowledge repertoire of EnergyCorp as a German multinational. The President and CEO, also an American, recounts how this enabled EnergyCorp to make a link to the home-country practice of apprenticeship training:

"And then we said, okay, now where do we get [...] a pipeline of workers to be able to fill the jobs inside the factory and again, we looked around and said, well, actually [Name of city of location] has good community colleges, good high schools, how could we mobilize some of the resources there [...]? And that is where we kind of made the link to the apprenticeship program we were already using and German companies were already using so successfully in Germany in terms of reaching already down into the high schools and getting some of the students ready for, let's say a vocational career" (President and CEO; U.S. Headquarters).

A first important observation is that EnergyCorp accessed the knowledge of an alternative course of action after being confronted with an important challenge, in this case, how to manage a rapid and significant expansion. 'Making the link' to apprenticeship involved members of the path-dependent entity leveraging the external lens of home-country colleagues, who did not face the path and thus were 
able to envision an alternative future. However, transitioning from conceiving apprenticeship as an alternative to actually implementing it required active engagement with the self-reinforcing mechanisms associated with the institutional path.

Meanwhile, the institutional path was deeply inscribed in the organization. For example, a manager who is originally from Germany, and, therefore, aware of apprenticeship, recounts his experience as follows:

“I was always, it was my management and HR who said, 'why don't we have an apprenticeship program like this?' So I was always focusing on this program and questioning why we do not have that. But there was also a good explanation for why we do not have that. Because when you look at this, no one else in the United States is doing this" (Production Manager; U.S. Subsidiary).

Doing something that very few others were doing entailed active engagement with the underlying mechanisms. Here, one dominant feature of institutional paths is the existence of strong coordination effects, which structure rule-guided behavior. At the level of firms, these effects materialize in formal job descriptions and informal routines, such as job shadowing for purposes of on-the-job training. Interrupting the 'logic and energy' of the specific coordination effects required EnergyCorp to make clear how established routines were failing to be effective, and to prepare the organization for an alternative course of action. The irritations this created were actually productive in interrupting existing mechanisms:

"There was still some resistance. It was something that had not been done here before. I think most managers think there are plenty of people out there on the streets who can do what they need for them to do, and that is not the case" (Training Manager; U.S. Subsidiary).

Complementarities between the sphere of education and training on the one hand, and the employment relations and human resources strategy on the other, had to be interrupted, too. In the past, the subsidiary in the U.S. followed a hire-and-fire approach, whereby talent was let go in response to crises. EnergyCorp sought to abandon these complementarities, and try to 'do things differently:'

"And I went in 2002, 2003, when we followed this American model, ramp down, ramp up, ramp down and up, and it took us, because it is not good, because it has a tremendous impact on productivity, it has a tremendous impact on non-conforming situations, a lot of non-conforming situations [...]. And then is when we laid people off. We are still probably recovering from that because we let skilled workforce go which we had trained over ten years, or longer, twenty years, they do not come back, we are starting all over. And now we are going to try that differently, you know, when we go through peaks and valleys, we have adjusted our manpower, it is all a question of management" (Production Manager; U.S. Subsidiary).

Departing from the previous strategy, the Director of Operations describes the radical new approach as follows: "We want to build our reputation as our best asset 
is our people, we take care of our people, and we do not [lay them off]" (Director of Operations; U.S. Subsidiary).

Furthermore, EnergyCorp had to actively engage with the learning effects associated with the path-dependent process. Applied to the case of vocational training, learning typically takes the form of organizations learning to better administer on-the-job training, and to better navigate within a certain set of institutional parameters. For example, organizations enjoy learning effects as they repeatedly engage in certain behavioral patterns, such as training un- or semi-skilled workers as part of the production process. EnergyCorp suspended this learning loop, and instead actively sought to learn from its German facilities on how to run an apprenticeship program. For example, managers and trainers visited Germany to see how EnergyCorp implements apprenticeships at home. Once the U.S. subsidiary had started its own apprenticeship program in 2011, a largely unintended effect of running a program with a yearly intake was that EnergyCorp was able to learn from year to year how to implement apprenticeship.

Finally, EnergyCorp also had to actively engage with the adaptive expectation effects of the institutional path. In the context of education pathways, adaptive expectations refer to the expected and normatively valued choices made by students. Over time, strong adaptive expectations have been formed in the U.S., centering on flexible on-the-job training as the dominant pathway into production jobs, while 4-year college degrees pave the way into middle management and white-collar jobs. Radically disrupting these adaptive expectations, EnergyCorp engaged in local as well as national activities to position apprenticeship as a new alternative. The outcome of these activities was that EnergyCorp slowly changed the 'paradigm' around apprenticeship, in students and parents, as well as high schools: "Just the paradigm, I think Americans have a real paradigm about vocational training and apprenticeship.[...] So I think we just had a huge paradigm shift, not only with the kids, but with our managers here and with the kids' parents. And also the teachers" (Training Manager; U.S. Subsidiary).

In sum, EnergyCorp was successful in 'fighting to break down' significant barriers related to the path-dependent process faced by its foreign subsidiary in the U.S.:

\begin{abstract}
"The barriers can be overcome. I think we have shown that they can absolutely be overcome. But that does not mean that we just continue to accept the barriers. What we are going to do is to fight to break them down, to make it more effective and efficient the way we do [apprenticeships]" (Executive; U.S. Headquarters).
\end{abstract}

Table 4 below summarizes our findings on how the mechanisms underlying the institutional path materialized at the level of the U.S. subsidiary of EnergyCorp, resulting in a diminished scope for maneuver, and how mechanisms interruption yielded regained scope for maneuver, resulting in the enabling of apprenticeship as path-deviant behavior. This process of regaining scope for maneuver was enabled by leveraging an external lens, taking the form of home-country operations within the wider MNC organization. Over time, mechanisms interruption achieved a slow rewinding of the path, and a future involving apprenticeship was embraced. 


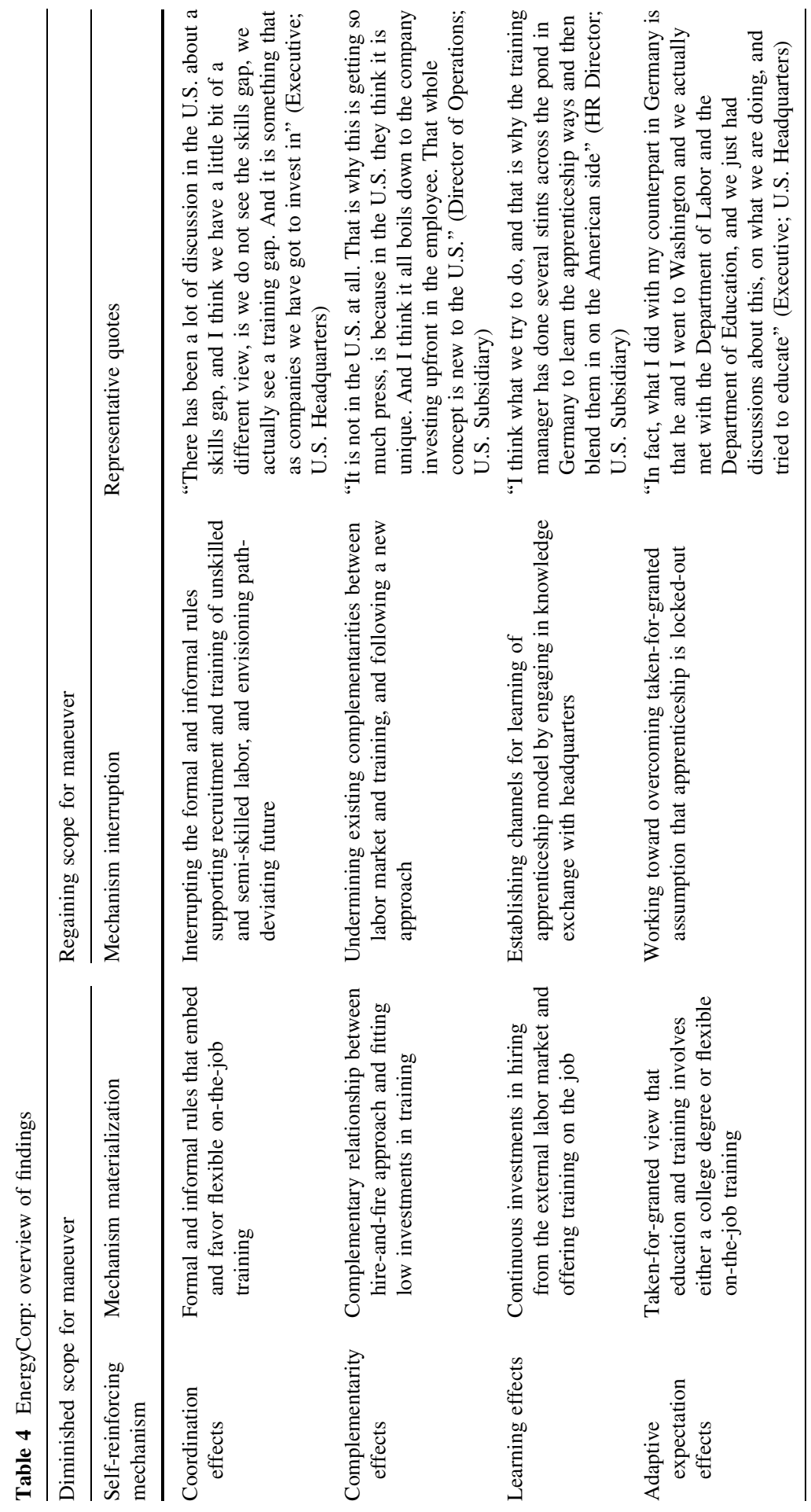




\section{Discussion}

Examining whether and how organizations can regain scope for maneuver after having reached the lock-in stage is arguably the research problem in 'strong' path dependence theorizing (Schreyögg 2014; Sydow et al. 2009). Previous research has emphasized agency at the back end of the process largely as contributing to the reproduction of existing rigidified behavioral patterns, with the path-dependent process significantly constraining agency and limiting its creativity to the horizontal dimension (Rothmann and Koch 2014). In this paper, we were interested in understanding under what conditions and how exactly organizations facing path dependence can exercise agency, not in the sense of reproducing but rather of transforming structures (see Emirbayer and Mische 1998). This is a critical research problem because it pushes us to account for the empirical observation that some organizations-against the odds-do indeed succeed in escaping from path dependence; and it also promises to move us closer to an evolutionary view on path dependence theorizing (see also Vergne and Durand 2011). In particular, further problematizing agency in and after lock-in helps us "focus on ongoing evolution rather than stability" (Martin 2010: 13) in path dependence, which opens up an exciting field of additional research questions for path dependence scholars.

Studying two cases and utilizing a replication logic for additional robustness (Eisenhardt and Graebner 2007), we develop the argument that regaining scope for maneuver is possible through engaging with the underlying self-reinforcing mechanisms. However, and lending further support to the outsider's ontology dominant in strong views on path dependence (e.g., David 1985), our empirical case material suggests that this requires an external lens. This is in line with prior research, which suggests the relevance of critical and subsequent series of events for destabilizing paths. More specifically, Wenzel et al. (2017: 362) show how paths "are broken by means of a process in which several critical events-including technological, administrative, and structural events—sequentially destabilize selfreinforcing mechanisms and strategic patterns." Similarly, seminal work establishes that external shocks "are likely to shape the system, thereby causing the organization to break away from the path" (Sydow et al. 2009: 701). Emirbayer and Mische (1998: 963) conceive of agency as embedded in 'contingencies of the moment,' and an external shock can radically alter these contingencies, and thus reshape the relational embeddedness of actors.

In our cases, the external lens was introduced at a particular point in time by a strategic investor and by being an $\mathrm{MNC}$, which infused the necessary degree of reflexivity to envision an alternative future. With the help of an external lens, our two cases were able to conceive 'fictions' (Beckert 2013) involving path-deviant behavior, in the processes regaining scope for maneuver. While the particular kind of external impetus as well as the precise mechanisms and their inscriptions in the organizations varied empirically across our two cases, our cross-case findings yield remarkably similar analytical insights, thus helping us to build theoretical arguments that are generalizable in an analytical sense (Yin 2017). 
Our findings enable theorization on why exactly the interruption of the logic of the self-reinforcing mechanisms enables an escape from path dependence (Sydow et al. 2009). Previous research shows how self-reinforcing mechanisms are inscribed in formal and informal organizational structures and routines (Koch 2011). Mechanisms are thus not only 'routinely incorporated in practical activity' (see Emirbayer and Mische 1998: 971) but also inscribed in the organizational structures that guide and support this practical activity. Tackling the research question of how mechanism interruption enables path-dependent organizations to regain scope for maneuver, we uncover the relationship between the working of self-reinforcing mechanisms and their inscription in corresponding formal and informal rules, and how interrupting the mechanisms can unsettle the inscribed pattern.

Previous work suggests that different manifestations of path dependence-selfreinforcing mechanisms and pattern-can be destabilized by different and largely unrelated events (Wenzel et al. 2017). Our paper moves toward a tighter integration of these manifestations and argues that the mechanisms interruption serves as a lever to overcoming the inscribed pattern. More specifically, we argue that the mechanism interruption needs to be sustained, to enable the slow unwinding of the inscribed path. Interrupting the 'logic and energy' of the self-reinforcing mechanisms is thus not a one-off activity, but needs to be accomplished over a period of time. Overall, our findings suggest that active engagement with the mechanisms for the purpose of interrupting them constitutes a key lever to rewind, indirectly but effectively, the 'pattern inscription' observed in cases of path dependence. Together, this mechanism-based theorizing (Davis and Marquis 2005) suggests a temporal perspective on how exactly organizations can regain scope for maneuver: by engaging with the self-reinforcing mechanisms, they not only interrupt the influence of the path-dependent dynamics on them, but also set in motion a process whereby inscribed rules and routines are slowly reversed and unwound. Our study adds to a temporal perspective on (escaping from) path dependence by suggesting a sequence involving first mechanisms interruption and then pattern unwinding.

Our paper complements previous work (Fortwengel and Jackson 2016), which has explored how the successful introduction of apprenticeship in the U.S. setting requires active engagement with the institutional pillars of the environment, by revealing how in path-dependent settings these pillars are brought about and sustained by self-reinforcing mechanisms. Likewise, our study also adds nuance to the broader literature on inertia and adaptation (Eggers and Park 2018) by highlighting the particular challenges and possible solutions when rigidified structures and inertial barriers (Tripsas and Gavetti 2000) are built up and (counterfactually) stabilized by self-reinforcing mechanisms.

Our theorization suggests that self-reinforcing mechanisms play a complex role in processes of path dependence. On the one hand, they are the key driver of path dependence, not least because they are constantly enacted as part of a more iterational and habitual form of agency (see Emirbayer and Mische 1998); on the other hand, paradoxically, they also offer a possible lever to escape path dependence. Previous research on path dependence has focused its attention on the shape and implications of mechanisms (cf., Dobusch and Schüßler 2013; Vergne and Durand 2010), and our theorization suggests that additional research on the 
complex role of mechanisms is promising to advance our understanding of the antecedents, materializations, consequences, and possible ways out of path dependence. This brings us to discussing the study's limitations as well as possible research frontiers.

\section{Limitations and outlook}

Although this study provides several new insights and theoretical contributions, like all empirical research it also has some limitations, which, however, open up promising avenues for future research. Most notably, our study and theorizing is based on only two (idiosyncratic) cases in their unique contexts. While studying and exploring two rare and revelatory instances (Ozcan et al. 2017; Siggelkow 2007) in which the phenomena and issues of interest are 'transparently observable' (Pettigrew 1990) does not permit statistical generalization, it allows for analytical generalization (Gibbert et al. 2008; Yin 2017) and thus offers the opportunity to build new and extend existing theory (Eisenhardt 1989; Lee 1999). Accordingly, we encourage future research to substantiate and further refine our findings by performing analyses across additional cases. For example, comparing successful and unsuccessful cases could yield additional insights into the necessary and sufficient conditions for regaining scope for maneuver. Likewise, we see promise in largescale quantitative analyses and other methodologies, such as experiments (cf., Koch et al. 2009) and simulations (cf., Petermann et al. 2019) to further advance our understanding not only of how self-reinforcing dynamics gradually build up and constrain organizations, but also how locked-in organizations can successfully break free from path dependence. As one further limitation of this study and of qualitative case-based research on path dependence in general concerns the retrospective reconstruction and mapping of self-reinforcing mechanisms (cf., Sydow et al. 2012a), these more controlled methods-while having other weaknesses such as difficulties in covering the complexity and temporal dynamics of social processesare particularly well suited to comprehensively measuring and displaying the precise working of distinct self-reinforcing mechanisms (Vergne and Durand 2010).

In regard to this study's concrete findings, we encourage future research to explore the conditions under which a particular path-dependent entity can attain the required reflexivity to detect and act on path dependence. While our study highlights the decisive role of an external impetus (cf., David 1986), previous work suggests that internal 'path monitoring' (Schreyögg and Kliesch-Eberl 2007)—in the form of an organizational surveillance system - may facilitate organizational actors' ability to "move 'beyond themselves' into the future and construct changing images of where they think they are going, where they want to go, and how they can get there from where they are at present" (Emirbayer and Mische 1998: 984). Relatedly, additional research is needed to help us better understand under what conditions an external impetus constitutes a trigger for agency out of path dependence, and when instead, it has only a limited, short-term effect (cf., Petermann et al. 2019) and thus leads to a continued (pathological) reproduction of the existing pattern (Wenzel 2015). Here, we suggest that a 'big event' such as a takeover, a leadership transition, 
and not a general but rather an issue-specific crisis increases the probability of pathdeviant change, while small and less disruptive events as well as more complex, time-lagged, and diffuse crisis situations are probably less likely to constitute triggers out of path dependence. However, this needs to be explored in future research.

We also encourage future research to explore more deeply the contextual factors, including the role of legitimate authority, social position, status, and power (cf., Magee and Galinsky 2008) that allow_or not—certain actors to work against and potentially interrupt self-reinforcing mechanisms within an organization. For example, in the case of CameraCorp, the investor's powerful position seems to have been a decisive factor enabling the effective interruption of the selfreinforcing dynamics. More generally, we see merit in zooming in more on the role of particular agents in processes of agency. For example, EnergyCorp leveraged an inter-organizational network for a number of years to change cognitions, norms, and rules pertaining to apprenticeship training (Fortwengel and Jackson 2016). This suggests that external actors can play an important role throughout the whole process, not only in terms of triggering the process, but actually also contributing to the (sustained) interruption and eventual rewinding of a path-dependent pattern.

Relatedly, we see promise in additional research unpacking further the precise processes of and relationship between mechanism interruption and the rewinding of inscribed patterns within the organization. Here, fine-grained ethnographic research over an extended period of time could yield important insights into both the organizational inscription of a path (Koch 2011) and how exactly mechanisms interruption and pattern unwinding is accomplished in and through day-to-day activities. Furthermore, we see promise in exploring exactly how long and sustained mechanisms interruption needs to be in place for the gradual unwinding of pattern inscription to occur. Here, it is conceivable that the timeline and necessary intensity may depend on the extent to which a path-dependent pattern is inscribed and diffused within one (Kremser and Schreyögg 2016) or multiple organizations (Koch 2008, 2011), including how many units and functions are subject to the particular path-dependent process. More broadly, this relates to the emerging understanding of organizational path dependence as a multi-level phenomenon, where one or even multiple self-reinforcing processes and paths operate at and potentially across different levels, possibly forming nested relationships. In conclusion, we believe that further examining the antecedents, moderating factors, and boundary conditions of the precise shape and implications of interrupting the 'logic and energy' (see Sydow et al. 2009) of a path's underlying mechanisms could offer intriguing insights into the temporality of ways out of path dependence, and more generally could enrich our understanding of organizational path dependence as a 'timely' concept.

Acknowledgements This research was conducted as part of the 'Pfadkolleg' at Freie Universität Berlin and supported by the German Research Foundation (DFG), which provided two separate grants (Grant Numbers GRK 1012 and FO 1024/1-1). We thank Elke Schüßler and Thomas Gehrig for editorial guidance, two anonymous reviewers for developmental feedback, which helped strengthen the paper considerably, and Jörg Sydow and Fredrik Tell for helpful comments on earlier versions of the paper. 
Open Access This article is licensed under a Creative Commons Attribution 4.0 International License, which permits use, sharing, adaptation, distribution and reproduction in any medium or format, as long as you give appropriate credit to the original author(s) and the source, provide a link to the Creative Commons licence, and indicate if changes were made. The images or other third party material in this article are included in the article's Creative Commons licence, unless indicated otherwise in a credit line to the material. If material is not included in the article's Creative Commons licence and your intended use is not permitted by statutory regulation or exceeds the permitted use, you will need to obtain permission directly from the copyright holder. To view a copy of this licence, visit http:// creativecommons.org/licenses/by/4.0/.

\section{References}

Argote, L. 1999. Organizational Learning: Creating, Retaining and Transferring Knowledge. Boston: Kluwer Academic.

Arthur, W.B. 1989. Competing technologies, increasing returns, and lock-in by historical events. Economic Journal 99 (394): 116-131.

Arthur, W.B. 1994. Increasing Returns and Path Dependence in the Economy. Ann Arbor: University of Michigan Press.

Arthur, W.B. 1996. Increasing returns and the new world of business. Harvard Business Review 74 (4): 100-109.

Beckert, J. 2013. Imagined futures: Fictional expectations in the economy. Theory and Society 42: 219-240.

Berthod, O., and J. Sydow. 2013. Locked in the iron cage? When institutionalization is (not) a pathdependent process. In Self-reinforcing dynamics in and among organizations, ed. J. Sydow and G. Schreyögg, 204-229. London: Palgrave Macmillan.

Burgelman, R.A. 2002. Strategy as vector and the inertia of coevolutionary lock-in. Administrative Science Quarterly 47 (2): 325-357.

Burgelman, R.A. 2010. Strategic consequences of co-evolutionary lock-in: Insights from a longitudinal process study. In The Hidden Dynamics of Path Dependence: Institutions and Organizations, ed. G. Schreyögg and J. Sydow, 233-248. New York: Palgrave Macmillan.

Burger, M., and J. Sydow. 2014. How inter-organizational networks can become path-dependent: Bargaining practices in the photonics industry. Schmalenbach Business Review 66 (1): 73-99.

Collier, R.B., and D. Collier. 1991. Shaping the Political Arena: Critical Junctures, the Labor Movement, and Regime Dynamics in Latin America. Princeton: Princeton University Press.

Cusumano, M.A., Y. Mylonadis, and R.S. Rosenbloom. 1992. Strategic maneuvering and mass-market dynamics: The triumph of VHS over Beta. Business History Review 66 (1): 51-94.

David, P.A. 1985. Clio and the economics of QWERTY. American Economic Review 75 (2): 332-337.

David, P.A. 1986. Understanding the economics of QWERTY: The necessity of history. In Economic History and the Modern Economist, ed. W.N. Parker, 30-49. Oxford: Blackwell.

David, P.A. 1994. Why are institutions the 'carriers of history'?: Path dependence and the evolution of conventions, organizations and institutions. Structural Change and Economic Dynamics 5 (2): 205-220.

Davis, G., and C. Marquis. 2005. Prospects for organization theory in the early twenty-first century: Institutional fields and mechanisms. Organization Science 16 (4): 332-343.

Dobusch, L., and E. Schüßler. 2013. Theorizing path dependence: A review of positive feedback mechanisms in technology markets, regional clusters, and organizations. Industrial and Corporate Change 22 (3): 617-647.

Duschek, S. 2010. Strategisches Pfadmanagement: 'Beyond Path Dependence' [Strategic path management: 'Beyond path dependence']. Managementforschung 20: 223-259.

Eggers, J.P., and K. Park. 2018. Incumbent adaptation to technological change: The past, present, and future of research on heterogeneous incumbent response. Academy of Management Annals 12 (1): 357-389.

Eisenhardt, K.M. 1989. Building theories from case study research. Academy of Management Review 14 (4): 532-550. 
Eisenhardt, K.M., and M.E. Graebner. 2007. Theory building from cases: Opportunities and challenges. Academy of Management Journal 50 (1): 25-32.

Emirbayer, M., and A. Mische. 1998. What is agency. American Journal of Sociology 103 (4): 962-1023.

Ennen, E., and A. Richter. 2010. The whole is more than the sum of Its parts - or is It? A review of the empirical literature on complementarities in organizations. Journal of Management 36 (1): 207-233.

Fortwengel, J., and G. Jackson. 2016. Legitimizing the apprenticeship practice in a distant environment: Institutional entrepreneurship through inter-organizational networks. Journal of World Business 51 (6): 895-909.

Fortwengel, J., H. Gospel, and P. Toner. 2019. Varieties of institutional renewal: the case of apprenticeship in the US, England, and Australia. Journal of Vocational Education \& Training. https://doi.org/10.1080/13636820.2019.1688855.

Garud, R., and P. Karnøe. 2001. Path creation as a process of mindful deviation. In Path Dependence and Creation, ed. R. Garud and P. Karnøe, 1-40. Mahwah: Lawrence Erlbaum.

Garud, R., S. Jain, and A. Kumaraswamy. 2002. Institutional entrepreneurship in the sponsorship of common technological standards: The case of Sun Microsystems and Java. Academy of Management Journal 45 (1): 196-214.

Garud, R., A. Kumaraswamy, and P. Karnøe. 2010. Path dependence or path creation? Journal of Management Studies 47 (4): 760-774.

Gibbert, M., W. Ruigrok, and B. Wicki. 2008. What passes as a rigorous case study? Strategic Management Journal 29 (13): 1465-1474.

Giddens, A. 1984. The Constitution of Society: Outline of the Theory of Structuration. Cambridge: Polity Press.

Glaser, B.G., and A.L. Strauss. 1967. The Discovery of Grounded Theory. Chicago: Aldine.

Hall, P.A., and D. Soskice. 2001. Varieties of Capitalism: The Institutional Foundations of Comparative Advantage. Oxford: Oxford University Press.

Katz, M.L., and C. Shapiro. 1985. Network externalities, competition, and compatibility. American Economic Review 75 (3): 424-440.

Kieser, A. 1994. Why organization theory needs historical analyses and how this should be performed. Organization Science 5 (4): 608-620.

Kipping, M., and B. Üsdiken. 2014. History in organization and management theory: More than meets the eye. Academy of Management Annals 8 (1): 535-588.

Koch, J. 2008. Strategic paths and media management: A path dependency analysis of the German newspaper branch of high quality journalism. Schmalenbach Business Review 60 (1): 50-73.

Koch, J., M. Eisend, and A. Petermann. 2009. Path dependence in decision-making processes: Exploring the impact of complexity under increasing returns. Business Research 2 (1): 67-84.

Koch, J. 2011. Inscribed strategies: Exploring the organizational nature of strategic lock-in. Organization Studies 32 (3): 337-363.

Kremser, W., and G. Schreyögg. 2016. The dynamics of interrelated routines: Introducing the cluster level. Organization Science 27 (3): 698-721.

Langley, A., C. Smallman, H. Tsoukas, and A.H. Van de Ven. 2013. Process studies of change in organization and management: Unveiling temporality, activity, and flow. Academy of Management Journal 56 (1): 1-13.

Lee, T.W. 1999. Using Qualitative Methods to Organize Research. Newbury Park: Sage.

Lerman, R.I. 2010. Apprenticeship in the United States: Patterns of governance and recent developments. In Rediscovering Apprenticeship, ed. F. Rauner and E. Smith, 125-136. New York: Springer.

Levinthal, D.A., and J.G. March. 1993. The myopia of learning. Strategic Management Journal 14: 95-112.

Magee, J.C., and A.D. Galinsky. 2008. Social hierarchy: The self-reinforcing nature of power and status. Academy of Management Annals 2 (1): 351-398.

Martin, R., and P. Sunley. 2006. Path dependence and regional economic evolution. Journal of Economic Geography 6 (4): 395-437.

Martin, R. 2010. Rethinking regional path dependence: Beyond lock-in to evolution. Economic Geography 86 (1): 1-27.

Milgrom, P., and J. Roberts. 1990. The economics of modern manufacturing: Technology, strategy, and organization. American Economic Review 80 (3): 511-528.

North, D.C. 1990. Institutions, Institutional Change and Economic Performance. Cambridge: Cambridge University Press. 
Ozcan, P., S. Han, and M.E. Graebner. 2017. Single cases: The what, why, and how. In The Routledge Companion to Qualitative Research in Organization Studies, ed. R.A. Mir and S. Jain, 92-112. New York: Routledge.

Petermann, A., G. Schreyögg, and D. Fürstenau. 2019. Can hierarchy hold back the dynamics of selfreinforcing processes? A simulation study on path dependence in hierarchies. Business Research 12 (2): 637-669.

Pettigrew, A.M. 1990. Longitudinal field research on change: Theory and practice. Organization Science 1 (3): 267-292.

Pierson, P. 2000. Increasing returns, path dependence, and the study of politics. American Political Science Review 94 (2): 251-267.

Porter, M.E., and N. Siggelkow. 2008. Contextuality within activity systems and sustainability of competitive advantage. Academy of Management Perspectives 22 (2): 34-56.

Rogers, J., and E. Parker. 1996. The Wisconsin Regional Training Partnership: Lessons for national policy. NCW Working Paper Series, vol. 3. Berkeley: National Center for the Workplace.

Rothmann, W., and J. Koch. 2014. Creativity in strategic lock-ins: The newspaper industry and the digital revolution. Technological Forecasting \& Social Change 83 (3): 66-83.

Salvato, C., and R. Vassolo. 2018. The sources of dynamism in dynamic capabilities. Strategic Management Journal 39 (6): 1728-1752.

Schmidt, T., and T. Braun. 2015. When cospecialization leads to rigidity: Path dependence in successful strategic networks. Schmalenbach Business Review 67 (4): 489-515.

Schreyögg, G., and M. Kliesch-Eberl. 2007. How dynamic can organizational capabilities be? Towards a dual-process model of capability dynamization. Strategic Management Journal 28 (9): 913-933.

Schreyögg, G., and J. Sydow. 2011. Organizational path dependence: A process view. Organization Studies 32 (3): 321-335.

Schreyögg, G., J. Sydow, and P. Holtmann. 2011. How history matters in organisations: The case of path dependence. Management \& Organizational History 6 (1): 81-100.

Schreyögg, G. 2014. Pfadabhängigkeit und Pfadbruch in Unternehmen [Path dependence and path breaking in companies]. Schmalenbachs Zeitschrift für betriebswirtschaftliche Forschung 68: 1-17.

Siggelkow, N. 2001. Change in the presence of fit: The rise, the fall, and the renaissance of Liz Claiborne. Academy of Management Journal 44 (4): 838-857.

Siggelkow, N. 2007. Persuasion with case studies. Academy of Management Journal 50 (1): 20-24.

Stieglitz, N., and K. Heine. 2007. Innovations and the role of complementarities in a strategic theory of the firm. Strategic Management Journal 28 (1): 1-15.

Suddaby, R., D. Coraiola, C. Harvey, and W. Foster. 2020. History and the micro-foundations of dynamic capabilities. Strategic Management Journal 41 (3): 530-556.

Sull, D.N. 1999. Why good companies go bad. Harvard Business Review 77 (4): 42-52.

Sydow, J., G. Schreyögg, and J. Koch. 2009. Organizational path dependence: Opening the black box. Academy of Management Review 34 (4): 689-709.

Sydow, J., F. Lerch, and U. Staber. 2010. Planning for path dependence? The case of a network in the Berlin-Brandenburg optics cluster. Economic Geography 86 (2): 173-195.

Sydow, J., A. Windeler, G. Müller-Seitz, and K. Lange. 2012a. Path constitution analysis: A methodology for understanding path dependence and path creation. Business Research 5 (2): 155-176.

Sydow, J., A. Windeler, C. Schubert, and G. Möllering. 2012b. Organizing R\&D consortia for path creation and extension: The case of semiconductor manufacturing technologies. Organization Studies 33 (7): 907-936.

Teece, D.J., G. Pisano, and A. Shuen. 1997. Dynamic capabilities and strategic management. Strategic Management Journal 18 (7): 509-533.

Thelen, K.A. 1999. Historical institutionalism in comparative politics. Annual Review of Political Science 2 (1): 369-404.

Thelen, K.A. 2004. How Institutions Evolve: The Political Economy of Skills in Germany, Britain, the United States, and Japan. Cambridge: Cambridge University Press.

Tripsas, M., and G. Gavetti. 2000. Capabilities, cognition, and inertia: Evidence from digital imaging. Strategic Management Journal 21 (10-11): 1147-1161.

Tsoukas, H., and R. Chia. 2002. On organizational becoming: Rethinking organizational change. Organization Science 13 (5): 567-582.

Vergne, J.-P., and R. Durand. 2010. The missing link between the theory and empirics of path dependence: Conceptual clarification, testability issue, and methodological implications. Journal of Management Studies 47 (4): 736-759. 
Vergne, J.P., and R. Durand. 2011. The path of most persistence: An evolutionary perspective on path dependence and dynamic capabilities. Organization Studies 32 (3): 365-382.

Wenzel, M. 2015. Path dependence and the stabilization of strategic premises: How the funeral industry buries itself. Business Research 8 (2): 265-299.

Wenzel, M., H.-T. Wagner, and J. Koch. 2017. The funeral industry and the internet: On the historical emergence and destabilization of strategic paths. European Journal of Information Systems 26 (4): $361-378$.

Yin, R.K. 2017. Case Study Research and Applications: Design and Methods. Los Angeles: Sage Publishing.

Publisher's Note Springer Nature remains neutral with regard to jurisdictional claims in published maps and institutional affiliations. 